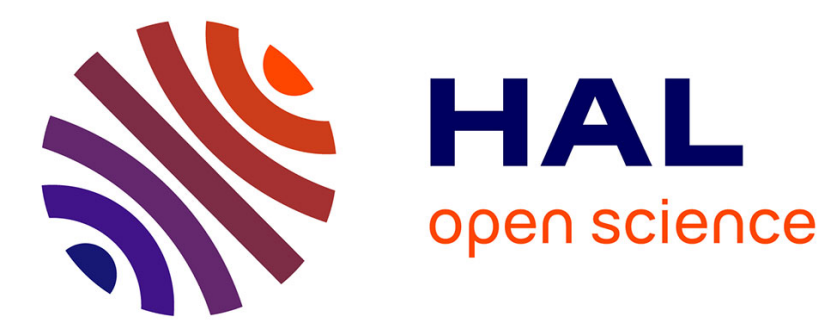

\title{
A statistical survey of ELF waves in a geostationary orbit
}

\author{
Michel Parrot, C. A Gaye
}

\section{To cite this version:}

Michel Parrot, C. A Gaye. A statistical survey of ELF waves in a geostationary orbit. Geophysical Research Letters, 1994, 21 (23), pp.2463-2466. 10.1029/94GL01700 . insu-03210017

\section{HAL Id: insu-03210017 https://hal-insu.archives-ouvertes.fr/insu-03210017}

Submitted on 27 Apr 2021

HAL is a multi-disciplinary open access archive for the deposit and dissemination of scientific research documents, whether they are published or not. The documents may come from teaching and research institutions in France or abroad, or from public or private research centers.
L'archive ouverte pluridisciplinaire HAL, est destinée au dépôt et à la diffusion de documents scientifiques de niveau recherche, publiés ou non, émanant des établissements d'enseignement et de recherche français ou étrangers, des laboratoires publics ou privés. 


\title{
A statistical survey of ELF waves in a geostationary orbit
}

\author{
M. Parrot and C.A. Gaye \\ Laboratoire de Physique et Chimie de l'Environnement, CNRS, Orléans, France
}

\begin{abstract}
GEOS 2 is a geostationary satellite that was launched with a wave experiment. The data provided during its lifetime ( -3.5 years) constitute a unique set for the statistical study of electromagnetic and electrostatic waves at $\mathrm{L}=6.6$. The aim of this paper is to present maps of the average intensity of the electric and magnetic field. The location of the more intense emissions up to $4.6 \mathrm{kHz}$ is shown as a function of local time and frequency. Such emissions are mainly composed of hiss, chorus and electroncyclotron harmonic $(\mathrm{ECH})$ waves. Their locations were specified and compared with data from the OGO 5 and SCATHA satellites. In particular, this study highlights the characteristics of chorus emissions with a gap at half the electron gyrofrequency. It is also shown that global magnetic activity only slightly influences wave amplitude.
\end{abstract}

\section{Introduction}

This paper presents a statistical study concerning the amplitude of ELF emissions recorded by the geostationary GEOS 2 satellite during several years. Electromagnetic waves observed in the magnetosphere below the electron gyrofrequency are mainly chorus and hiss. These whistlermode emissions have been known since a long time (Tsurutani and Smith, 1974; Burtis and Helliwell, 1976), but their generation mechanism is still under discussion (Cornilleau-Wehrlin et al., 1993a, and references therein). General characteristics of the waves observed by the GEOS 1 and GEOS 2 satellites are described by Cornilleau-Wehrlin et al. [1978]. Detailed analysis of events concerning hiss and chorus emissions was made by Hayakawa et al. [1984], and Parrot and Lefeuvre [1986]. Evidence of pitch angle scattering of energetic electrons due to cyclotron resonance with chorus waves has been presented by Foster and Rosenberg [1976]. A substorm dependence of these chorus emissions was noted (e.g. Tsurutani and Smith, 1977; Curtis, 1978; Isenberg et al., 1982). In the frequency range we have investigated, i.e. 0 . - $4.6 \mathrm{kHz}$, electrostatic waves known as electron-cyclotron harmonic $(\mathrm{ECH})$ waves are also present and tend to occur at $(n+1 / 2) f_{c o}$, where $f_{c}$ is the electron gyrofrequency. These ECH waves were intensively studied on GEOS 2 by Gouph et al. [1981], and Belmont et al. [1983]. Their importance in the diffuse auroral electron precipitation was investigated by Belmont et al. [1983], Canu

Copyright 1994 by the American Geophysical Union.

Paper number 94GL01700

0094-8534/94/94GL-01700\$03.00 et al. [1984], and Roeder and Koons [1989]. The last two authors have used data from the AMPTE-IRM satellite (elliptical orbit with a $28.6^{\circ}$ inclination) and the SCATHA satellite (equatorial orbit with a $7.78 \mathrm{R}_{\mathrm{E}}$ apogee and a 5.32 $R_{E}$ perigee); they have also statistically analyzed the equatorial magnetospheric wave activity observed by SCATHA (Koons and Roeder, 1990). Unlike the present paper, their work is related to visual inspection of daily spectrograms, in order to determine the nature of the wave emissions and their relative occurrence in local time. Section 2 of this paper is devoted to a short description of the GEOS 2 wave experiment and to the data that were used. Statistics and comparisons with previous analyses are given in section 3. Finally, conclusions are presented in section 4 .

\section{The data}

The GEOS 2 satellite was launched into a geostationary orbit in July 1978, with a wave experiment (S-300) similar to that of the GEOS 1 satellite. Only data from step frequency analyzers (SFA's) are used in this paper. For a detailed description of the GEOS S-300 experiment, see $S$ 300 Experimenters [1979]. The SFA's could sweep in the range $0-77 \mathbf{k H z}$, either between two predetermined frequency steps, or between two frequency steps automatically determined to register the most intense signals. However, the signals were mainly recorded between $0 .-4.6 \mathrm{kHz}$, the minimum duration of a frequency step being $86 \mathrm{~ms}$.

The data were recorded 24 hours per day and two types of records were produced: raw data with the time resolution of the experiment, and compressed data in order to select the most interesting part of the raw data. The compressed data contain average values of waveforms over $86 \mathrm{~ms}$ (the factor of compression was 128) for a given frequency step.

For the purpose of our statistical work, the compressed data were again averaged over 10 minutes for the different frequency steps between 150 and $4650 \mathrm{~Hz}$. Our data set contains the amplitude spectrum of one electric and one magnetic component as a function of days and local time. Data from July 26, 1978, until July 31, 1980, and from February 1, 1981, until June 30, 1982, were taken into account. This corresponds to measurements performed during roughly 20,000 hours because sometimes the S-300 experiment was outside our frequency range of investigation or was in an active mode.

\section{The results}

All data are summarized in Figures 1 and 3, which represent respectively the average values of the magnetic and 


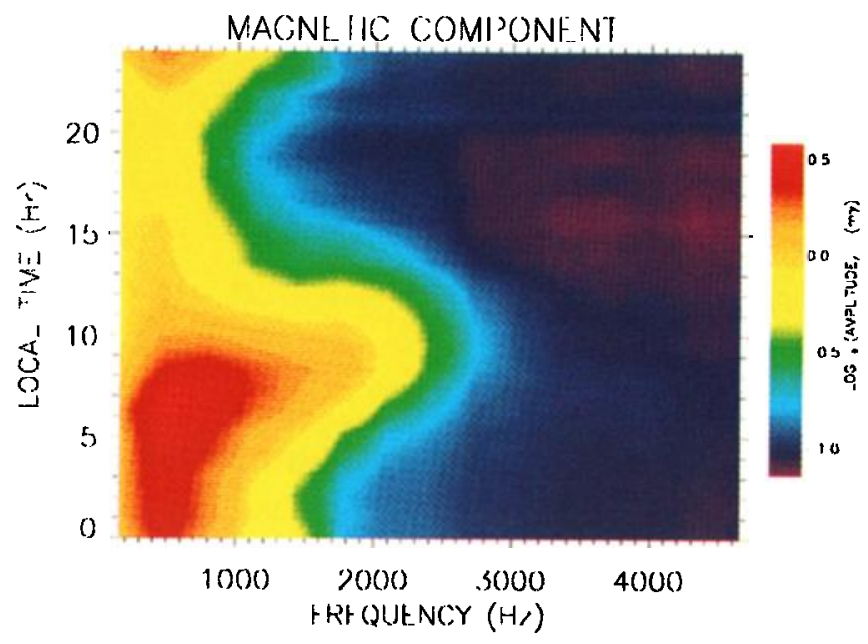

Figure 1. Average intensity of the magnetic signal recorded by the geostationary satellite GEOS 2 . The amplitude is represented as a function of local time and frequency, and colour-coded according to the scale on the right.

electric intensities. The data were first averaged in batches of one hour and one frequency step, and shown as a function of local time and frequency. Therefore, they are smoothed, and colour-coded according to the scale on the right. Concerning the magnetic component, the maximum intensity is observed in Figure 1 between 400 and $700 \mathrm{~Hz}$ and mainly between 0 $\mathrm{LT}$ and $9 \mathrm{LT}$, with a maximum peak around $6 \mathrm{LT}$. This point is more clear in Figure 2 where the average magnetic intensity at $450 \mathrm{~Hz}$ is represented as a function of local time. Between 6 and 8 LT, strong wave activity can be also observed up to $1.3 \mathrm{kHz}$. No intense waves are detected between 16 and 22 LT. The maximum average magnetic intensity corresponds to $5 \mathrm{~m} \gamma$. The electric component in Figure 3 also presents a maximum at the same location, but in addition electrostatic waves can be seen between 2.1 and $3.4 \mathrm{kHz}$, and 23 and $2 \mathrm{LT}$. The maximum average electric intensity of all emissions in Figure 3 is $12 \mu \mathrm{V} / \mathrm{m}$.

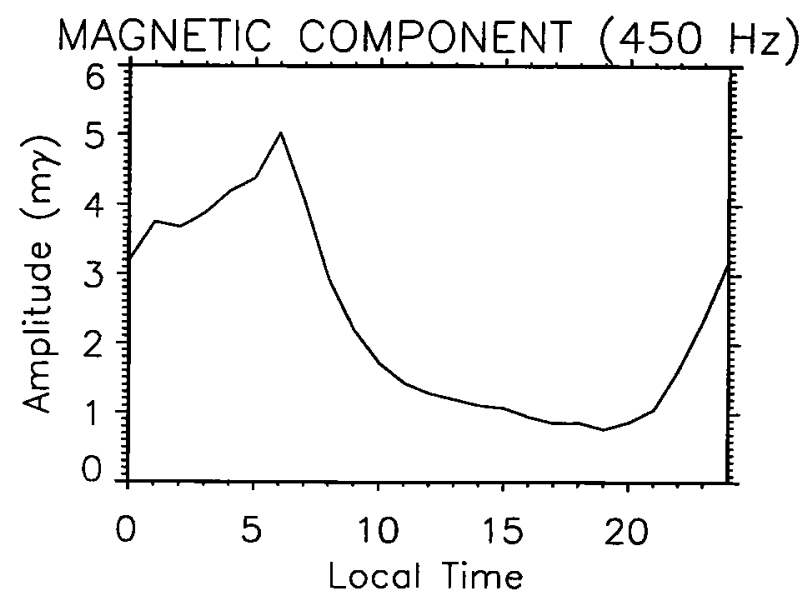

Figure 2. From the data set shown in Figure 1, amplitude of the average intensity of the magnetic signal at $450 \mathrm{~Hz}$ represented as a function of local time.

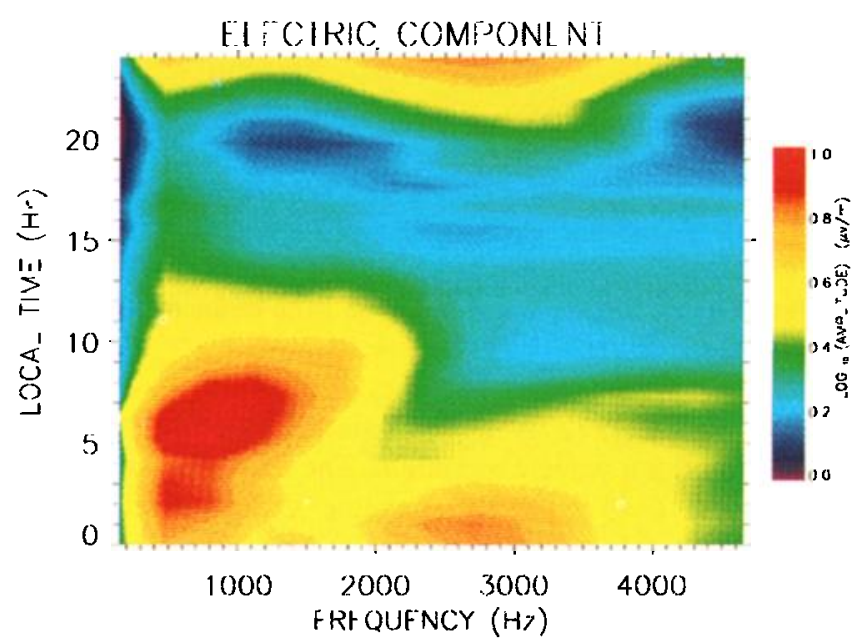

Figure 3. Same as in Figure 1 but for the electric signal.

The lack of emissions between 16 and $22 \mathrm{LT}$ occurred when GEOS 2 was located inside the plasmasphere in the bulge. According to Higel and Wu lei [1984], the average local time of bulge crossing by GEOS 2 was around $18 \mathrm{LT}$, and showed that this local time and the duration of crossing the bulge depended on magnetic activity. This lack of emissions was also observed with OGO 5 by Tsurutani and Smith [1977], and with SCATHA by Koons and Roeder [1990].

The emissions, which are mainly located between 400 and $700 \mathrm{~Hz}$, are certainly a mixture of hiss and chorus. Preliminary observations with GEOS 1 by CornilleauWehrlin et al. [1978] have indicated that very commonly hiss and chorus occur together. They have shown that chorus are mainly observed well before dawn and up to noon, whereas hiss are more present from noon to dusk. This is consistent with our observations, which show that, because chorus intensity generally is higher than hiss intensity, the maximum amplitude in Figures 1 and 3 is observed between 0 and 9 LT. This result is confirmed by SCATHA observations (Koons and Roeder, 1990). Hiss and chorus generally occur in the same frequency band, except when chorus are composed of two frequency bands: one above $f_{c o} / 2$, and the other below $\mathrm{f}_{\mathrm{co}} / 2$ (Tsurutani and Smith, 1974; Anderson and Maeda, 1977). Different mechanisms to explain this frequency gap are generally invoked. Tsurutani and Smith [1974] ascribed the gap to a Landau damping mechanism, whereas Maeda et al. [1976] proposed a two-source model. Curtis [1978] suggested that the lower emission is represented by whistler noise, and the upper emission by ordinary mode emissions.

Visual inspection of spectrograms recorded at regular intervals during the GEOS 2 lifetime, have shown that hiss bands are never above $1 \mathrm{kHz}$. Therefore, our statistics indicate that the characteristic two-banded chorus emissions are mostly observed between 6 and $12 \mathrm{LT}$, when the frequency of the more intense electromagnetic emissions increases up to $2.2 \mathrm{kHz}$. At this local time the average value of $f_{c e} / 2$ is about $1.3 \mathrm{kHz}$, but the fluctuation of this quantity does not allow a real determination of the gap between the 
two chorus bands. During the same time interval we notice that, first, the lower frequency band is consistently more intense than the upper frequency band, and, second, that the more intense emissions occur at the beginning, between 6 and 9 LT. This general observation is well supported by a case study by Hayakawa et al. [1984], who investigated all chorus emissions with GEOS 2 for a specific day. Koons and Roeder [1990] deduced from SCATHA data that there is no distinction in local time between chorus containing a gap at $f_{c o} / 2$ and others, because they only surveyed the occurrence and not the intensity of the emissions. GEOS 2 data, however, show chorus emissions with a gap at $f_{c d} / 2$ for different local times (Hayakawa et al., 1984), but their discrete elements were fewer in number and their amplitudes much lower. This observation of strong two-banded chorus emissions between 6 and 9 LT must be considered in the future to explain their generation mechanism. For example, the enhancement of chorus in this time interval fits well with mechanism of intensification of the loss cone instability due to the inclusion of thermal plasma from the sunlit ionosphere (Jentsch, 1976; Tsurutani and Smith,1977).

The electrostatic emission around $2.7 \mathrm{kHz}$, seen in Figure 3 between 23 and $2 \mathrm{LT}$, corresponded to the first harmonic $(n=1)$ of ECH waves occurring at $(n+1 / 2) f_{c c}$. The more intense emissions occurred at $2.7 \mathrm{kHz}$ and around 1 LT. This observation specifies and confirms the general results of Canu et al. [1984], who investigated with GEOS 2 the ECH waves up to $77 \mathrm{kHz}$. However, the location in local time of the SCATHA ECH emissions, presented by Koons and Roeder [1990], is more centred around 6 LT.

Figures 1-3 were obtained for all levels of magnetic activity. If we now consider the same statistics for different levels of magnetic activity, the positions of the maximum wave intensity do not significantly vary and only maximum average values change. For example, we respectively obtain $10 \mathrm{~m} \gamma$ and $24 \mu \mathrm{V} / \mathrm{m}$ for the magnetic and electric components when we only take into account the emissions with $\mathrm{AE}>300$. In this last calculation, we considered that the equatorial chorus are substorm related (e.g. Tsurutani and Smith, 1977): the drift time of $25 \mathrm{keV}$ electrons from midnight to GEOS 2 was introduced. A search of the more intense values of our data set was thus made, and the maximum value of the magnetic component (averaged over 10 minutes) now is $1.04 \gamma$. The maximum value of the electric component is $0.73 \mathrm{mV} / \mathrm{m}$, and the maximum intensity of the first harmonic of the $\mathrm{ECH}$ waves is $0.69 \mathrm{mV} / \mathrm{m}$. This relatively small maximum value measured in the nightside during all the GEOS 2 lifetime confirm the observations of Belmont et al. [1983], and their hypothesis that diffuse auroras are not only due to $\mathrm{ECH}$ waves.

\section{Conclusions}

Compared with previous studies, we have presented more detailed statistics of emissions observed at $L=6.6$ up to $4.6 \mathrm{kHz}$. Average spectrograms (frequency, local time) of one electric and one magnetic component were discussed. Concerning the amplitude, the main conclusions are: i) the most intense electromagnetic emissions occur at a frequency of 400 to $700 \mathrm{~Hz}$, and at a local time between 0 and $9 \mathrm{LT}$, ii) the most intense electrostatic emissions occur at a frequency of 2.1 to $3.4 \mathrm{kHz}$, and at a local time between 23 and 2 LT, iii) the most intense chorus emissions with a gap at $\mathrm{f}_{\mathrm{co}} / 2$ occur at a local time between 6 and 9 LT. Magnetospheric substorms (AE > 300) do not trigger emissions in other places and only enhance their maximum average amplitudes by a factor of 2 .

In the future, it is expected that new investigations will be part of the ISTP (International Solar-Terrestrial Physics) programme with the projects CLUSTER and EQUATOR-S. The frequency range of our statistical study is similar to that of the planned CLUSTER wave experiment (CornilleauWehrlin et al., 1993b).

Acknowledgments. Thanks are due to P. Crozet for his help during the data handling. The authors are grateful to the referees for their useful comments.

\section{References}

Anderson, R.R., and K. Maeda, VLF emissions associated with enhanced magnetospheric electrons, $J$. Geophys. Res., 82, 135-146, 1977.

Belmont, G., D. Fontaine, and P. Canu, Are equatorial electron cyclotron waves responsible for diffuse auroral precipitation?, J. Geophys. Res., 88, 9163-9170, 1983.

Burtis, W.J., and R.A. Helliwell, Magnetospheric chorus: occurrence patterns and normalized frequency, Planet. Space Sci., 24, 1007-1024, 1976.

Canu, P., G. Belmont, and D. Fontaine, Role of the equatorial ECH waves in the generation of diffuse auroras, ESA SP-217, 581-584, 1984.

Cornilleau-Wehrlin, N., R. Gendrin, F. Lefeuvre, M. Parrot, R. Grard, D. Jones, A. Bahnsen, E. Ungstrup, and W. Gibbons, VLF electromagnetic waves observed onboard GEOS 1, Space Sci. Rev., 22, 371-382, 1978.

Cornilleau-Wehrlin, N., J. Solomon, A. Korth, and G. Kremser, Generation mechanism of plasmaspheric ELF/VLF hiss: A statistical study from GEOS 1 data, J. Geophys. Res., 98, 21,471-21,479, 1993a.

Cornilleau-Wehrlin, N., et al., STAFF (Spatio Temporal Analysis of Field Fluctuations) experiment for the CLUSTER mission, ESA SP-1159, 33-48, $1993 \mathrm{~b}$.

Curtis, S.A., A theory for chorus generation by energetic electrons during substorms, J. Geophys. Res., 83, 38413848, 1978.

Foster, J.C., and T.J. Rosenberg, Electron precipitation and VLF emissions associated with cyclotron resonance interactions near the plasmapause, J. Geophys. Res., 81, 2183-2192, 1976.

Gouph, M.P., P.J. Christiansen, and E.J. Gershuny, ES wave morphology near geostationary orbit, Adv. Space Res., 1, 337-343, 1981.

Hayakawa, M., Y. Yamanaka, M. Parrot, and F. Lefeuvre, The wave normals of magnetospheric chorus emissions observed on board GEOS 2, J. Geophys. Res., 89, 28112821, 1984.

Higel, B., and Wu Lei, Electron density and plasmapause characteristics at $6.6 \mathrm{R}_{\mathrm{E}}$ : A statistical study of the 
GEOS 2 relaxation sounder data, J. Geophys. Res., 89, 1583-1601, 1984.

Isenberg, P.A., H.C. Koons, and J.F. Fennell, Simultaneous observations of energetic electrons and dawnside chorus in geosynchronous orbit, J. Geophys. Res., 87, 1495$1503,1982$.

Jentsch, V., Electron precipitation in the morning sector of the auroral zone, J. Geophys. Res., 81, 135-146, 1976.

Koons, H.C., and J.L. Roeder, A survey of equatorial magnetospheric wave activity between 5 and $8 R_{E}$, Planet. Space Sci., 38, 1335-1341, 1990.

Maeda, K., P.H. Smith, and R.R. Anderson, VLF emissions from ring current electrons, Nature, 263(5572), 37-39, 1976.

Parrot, M., and F. Lefeuvre, Statistical study of the propagation characteristics of ELF hiss observed on GEOS 1, inside and outside the plasmasphere, Annales Geophysicae, 4A, 363-384, 1986.

Roeder, J.L., and H.C. Koons, A survey of electron cyclotron waves in the magnetosphere and the diffuse auroral electron precipitation, J. Geophys. Res., 94, 2529-2541, 1989.
S300 Experimenters, Measurements of electric and magnetic wave fields and of cold plasma parameters on-board GEOS 1. Preliminary results, Planet. Space Sci., 27, 317-339, 1979.

Tsurutani, B.T., and E.J. Smith, Postmidnight chorus: a substorm phenomenon, J. Geophys. Res., 79, 118-127, 1974.

Tsurutani, B.T., and E.J. Smith, Two types of magnetospheric ELF chorus and their substorm dependences, $J$. Geophys. Res., 82, 5112-5128, 1977.

C.A. Gaye and M. Parrot, Laboratoire de Physique et Chimie de l'Environnement, 3A, Avenue de la Recherche, 45071 Orléans Cedex 02, France (e-mail:mparrot@cnrs-orleans.fr).

(Received: December 10, 1990;

Revised: February 04, 1991;

Accepted: April 15, 1991.) 